\title{
Natural Language Processing untuk Analisis Sentimen Presiden Jokowi Menggunakan Multi Layer Perceptron
}

Natural Language Processing for President Jokowi Sentiment Analysis using Multi Layer Perceptron

Nico Munasatya ${ }^{1}$, Sendi Novianto ${ }^{2}$

Fakultas Ilmu Komputer, Program Studi Teknik Informatika, Universitas Dian Nuswantoro

E-mail: ${ }^{1} 111201710512 @$ mhs.dinus.ac.id, ${ }^{2}$ sendi.novianto@dsn.dinus.ac.id

\begin{abstract}
Abstrak
Analisis sentiment biasa digunakan untuk opini minning dalam artian memberikan sebuah identitas/label (Positif, Negatif, Neutral) kedalam data/corpus.NLP (Natural Language Processing) digunakan untuk mengolah data/corpus agar dapat dipahami/dimengerti oleh mesin atau bisa dikatakan data preprocessing/cleaning text.Teks klasifikasi digunakan untuk memproses data/corpus dimasukan kedalam model mesin klasifikasi menggunakan model Multi-layer perceptron yang nantinya akan menghasilkan sebuah prediksi persentase akurasi > 90\% (lebih baik).Visualisasi data yang digunakan untuk mempresentasikan hasil dari model mesin yang merupakan supervised learning.Model selection digunakan untuk memperbaiki hasil persentase akurasi dari model mesin yang dilatih tadi, untuk model selection bisa memakai model Monte Carlo cross-validation. Hasil pengujian pada sistem yang dibangun didapatkan nilai akurasi hingga $93,26 \%$.
\end{abstract}

Kata kunci : Analisis Sentimen, Natural Language Processing, Multi-layer perceptron, Monte Carlo cross-validation

\begin{abstract}
Sentiment analysis is usually used for opinion minning in the sense of providing an identity / label (Positive, Negative, Neutral) into data / corpus. NLP (Natural Language Processing) is used to process data / corpus so that it can be understood / understood by machines or can be said preprocessing data / cleaning text. Classification text is used to process data / corpus entered into the classification engine model using the Multi-layer perceptron model which will later produce a prediction of accuracy percentage $>90 \%$ (better). Visualization of the data used to present the results of the machine model is a supervised learning. Model selection is used to improve the results of the percentage accuracy of the machine model that was trained, for the model selection can use the Monte Carlo cross-validation model. The results of testing on the system built obtained an assessment of up to $93.26 \%$.
\end{abstract}

Keywords : Sentiment Analysis, Natural Language Processing, Multi-layer perceptron, Monte Carlo cross-validation

\section{PENDAHULUAN}

Opini publik banyak sekali didalam media sosial contohnya ditwitter ,tiap menit bahkan detik banyak sekali orang-orang yang menuliskan opininya terhadap sebuah objek .kemudian isi dari opini tersebut ada yang aktual maupun yang tidak dan opini tersebut ada yang positif dan negatif dalam artian isi dari konteks opini tweet terhadap objek.maka dari itu ada ilmu yang mempelajari/menganalisis suatu objek kemudian objek tersebut berisi opini positif dan negatif nama ilmu tersebut adalah analisis sentimen[1]. Analisis sentimen termasuk kategori didalam text mining yang menggali data didalam suatu sumber informasi bisa diweb misal didalam penelitian ini adalah twitter dan dalam permasalahan penilitan ini adalah analisis sentimen sebuah metode untuk menganalisis opini publik terhadap suatu objek dalam implementasinya banyak sekali cara 
misalnya disini analisis sentimen [2] bagaimana menggunakan Natural Language Processing (NLP) untuk proses pre-processing dan model klasifikasi biner untuk analisis sentimen menggunakan algoritma multi layer perceptron sehingga penlitian ini menggunakan dua metode berbeda yang digabungkan dalam satu model mesin sebagai pembentukan pipeline [3][4].Tahapan pertama sebelum melakukan NLP terhadap dataset/corpus.Dataset/corpus didapatkan dari web minning,crawling tweet secara realtime sehari tiga kali sehari menggunakan lang-en (English), kemudian dianalisis sentiment menggunakan lexicon based bisa dikatakan pemberian label kepada corpus/dataset yang dilakukan perhitungan polarity dengan kamus kata (WordNet) [5].Kemudian tahapan kedua berikutnya untuk penilitian ini menggunakan metode atau algoritma multi layer perceptron dalam proses klasifikasi biner dalam menganalisis sentimen tweet presiden jokowi ditwitter dengan tujuan untuk mengetahui hasil akurasi dari model mesin dengan menggunakan algoritma multi layer perceptron.Dalam penelitian terkait Analisis Sentimen Mahasiswa Terhadap Fasilitas Universitas Telkom Menggunakan Metode Jaringan Saraf Tiruan Dan Tf-Idf [4] yang menggunakan metode sama dengan penilitian ini yaitu samasama menggunakan metode multi-layer perceptron yaitu cabang dari jaringan saraf tiruan,tetapi ada kelemahan didalam penelitian terkait yaitu pengumpulan datanya masih menggunakan kuisoner dan pemberian label positif atau negatif terhadap mahasiswa masih dilakukan manual.Sehingga dipenilitan ini akan dilakukan crawling data tweet menggunakan metode Natural Language Processing yang mendapatkan hasil text serta label yang sudah otomatis didapatkan dari proses metode tersebut.

\section{METODE PENELITIAN}

\subsection{Dataset}

Di bagian ini, penulis menjelaskan proses pengumpulan dan anotasi tweet pengujian mulai tahun 2020, termasuk yang sarkastik, dan kalimat yang terkandung dari tweet terhadap presiden jokowi.[6].Dataset dicrawling dari http://my-niconic.herokuapp.com/ dengan memasukan kata kunci yang dicari adalah presiden jokowi.

\subsection{Preprocessing}

Prepocessing disini merupakan tahapan untuk mengubah struktur sebuah corpus yang didalamnya berupa kumpulan text menjadi token atau kata lewat tahapan tokenization, token tersebut diolah lagi lewat tahapan proses stemming dan stopwords removal agar token tersebut tidak mengulangsi kata yang sama dan menjadi kata dasar. Balancing data, sebelum corpus dimasukan kedalam model klasifikasi masalah utama adalah dicorpus/datasetnya akan terjadi bahwa corpus dengan label positif dan negatif yang tidak seimbang maka dari itu diperlukan balancing data dengan cara smoothing dengan library imblearn atau Smote, corpus dijadikan satu feature kemudian diduplikasi dan juga dropout sehingga bisa menghindari overfitting data atau imbalencing data [7].Baru kemudian tahap selanjutnya adalah vectorizer yaitu pengubahan token atau kata menjadi sebuah vector agar dapat diolah kedalam algoritma machine learning.Proses terkahir adalah bag of words yaitu pengumpulan vector-vector yang sudah diproses ditahap vectorizer tadi, semua proses tadi terdapat pada sebuah pipeline NLP (Natrual Language Processing).[8] [9]

\subsection{Model yang diusulkan}

Model yang diusulkan pada penilitian ini ada pada gambar 1

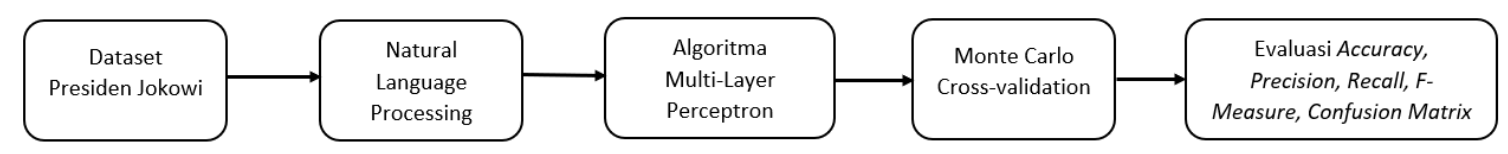

Gambar 1. Model yang diusulkan 
1. Dataset

Dataset diperoleh dari crawling data twitter secara realtime 1 hari 1-3x.Final Dataset diperoleh Corpus sejumlah 42 dimana tiap-tiap corpus berisi 90-100 baris kalimat dengan 3 kolom yaitu label/sentiment, teks/tweet dan user.Kemudian semua corpus yang berjumlah 42 digabung menjadi final dataset dengan total 3686 baris dan 3 kolom.[4]

2. NLP (Natural Language Processing)

Dalam perjalannya NLP dikenal sebagai process pengolahan teks dimana mesin tidak bisa memahami bahasa natural dari manusia maka perlu dibantu dengan adanya natural language procesing [3]. Dalam pembentukan sebuah NLP memerlukan sebuah pipeline dimana untuk model mesin yang dibuat dalam paper ini hanya menggunakan tahapan : (1) Word tokenization, (2) Stopwords removal, (3) Stemming, (4) Build bag of words, (5) Split datasets, (6) Vectorizer.[10][11][12]

Contoh teks/corpus : (1) @BadmintonTalk @jokowi MISSION COMPLETE PAK @ jokowi label positif, (2) What Jokowi's new cabinet means for Indonesian civil society https://t.co/dV56DeVJSA label positif. Setelah dilakukan teks preproses menggunakan NLP akan menjadi seperti ini : (1) badmintontalk jokowi mission complet pak jokowi label 1, (2) jokowi new cabinet mean indonesian civil societi label 1.

3. Algoritma Multi-Layer Perceptron

Perceptron dikenal sebagai bagian jaringan saraf yang dikenalkan pada tahun 1950-an, adalah algoritma sederhana untuk melakukan sebuah klasifikasi biner yaitu memprediksi apakah sebuah input termasuk dalam kategori ya atau tidak atau dalam biner (-1 dan 1) [13].Sebuah perceptron digolongkan linier yang artinya digunakan untuk memisahkan kategori dengan garis lurus.Input biasanya merupakan sebuah vektor x yang kemudian dikalikan dengan bobot $\mathrm{w}$ dan ditambahkan ke bias atau y sebagai berikut. [14]

$$
\begin{aligned}
& y=w \cdot x+b \\
& y=\varphi\left(\sum_{i=1}^{n} w_{i} x_{i}+b\right) \\
& y=\varphi\left(w^{T} x+b\right)
\end{aligned}
$$

Dimana : $\mathrm{y}$ adalah persamaan bias, $\mathrm{w}$ adalah bobot, $\mathrm{x}$ adalah vektor input, $\mathrm{b}$ adalah bias, phi adalah fungsi aktivasi non linier.

Dalam implementasi algoritma multi-layer perceptron untuk klasifikasi menggunakan backpropogation.[4]

$$
\begin{gathered}
\delta_{k}=\left(t_{k}-y_{k}\right) f^{\prime}\left(y_{-} n e t_{k}\right) \\
\delta_{k}=\left(t_{k}-y_{k}\right) y_{k}\left(1-y_{k}\right)
\end{gathered}
$$

Selanjutnya menghitung suku perubahan bobot $\mathrm{w}_{k j}$ dengan laju percepatan a dengan persamaan sebagai berikut :[1]

$$
\Delta w_{k j}=\alpha \cdot \delta_{k} \cdot z_{j}
$$

Selanjutnya dilakukan menghitung $\delta$ unit tersembunyi berdasar pada error pada tiap unit yang sembunyi dengan persamaan sebagai berikut :[1] 


$$
\delta_{n e t_{j}}=\sum_{k=1}^{m} \delta_{k} w_{k j}
$$

Terakhir $\delta$ unit tersembunyi direpresentasikan dari persamaan dibawah ini : [1]

$$
\begin{aligned}
& \delta_{j}=\delta_{n e t_{j}} f^{\prime}\left(Z_{\text {net }_{j}}\right) \\
& \delta_{j}=\delta_{-} n e t_{j} z_{j}
\end{aligned}
$$

Model algoritma klasifikasi multi-layer perceptron menggunakan fungsi aktifasi relu dengan rumus sebagai berikut :

4. Monte Carlo Cross-Validation

Monte Carlo Cross-Validation bekerja berbeda dengan cross validation karena monte carlo pemilihan data dilakukan secara acak didalam set pelatihan .Kemudian ditetapkan sisa data dari set pelatihan digunakan untuk menetapkan poin ke set tes. Proses ini diulang beberapa kali untuk menghasilkan sebuah set pelatihan secara acak baru dan diuji partisi setiap waktu atau bisa dikatakan pengujian dilakukan tiap iterasi yang menghasilkan sebuah set tes yang berbeda.Karena partisi dilakukan independen pada setiap model berjalan ,tititk yang sama dapat muncul di set pelatihan beberapa kali, disinilah pembeda antara mode carlo dengan validasi silang(Cross Validation).Untuk cross-validation dilakukan iterasi sebanyak 10 dengan menghasilkan evaluasi yang berbeda pada tiap iterasi. [10]

5. Evaluasi Accuracy, Precision, Recall, F-Measure, Confusion Matrix

Evaluasi dilakukakn untuk mengamati kinerja model algoritma dari multi-layer perceptron yang meliputi accuracy, precision, recall, F-measure, confusion matrix.Pertama untuk mengukur kinerja model multi-layer perceptron akan dilakukan pada confusion matrix.[15]

Tabel 1 Tabel Confusion Matrix

\begin{tabular}{|c|c|c|}
\hline \multirow{2}{*}{ Realita } & \multicolumn{2}{|c|}{ Prediksi } \\
\cline { 2 - 3 } & TN & FP \\
\cline { 2 - 3 } & FN & TP \\
\hline
\end{tabular}

Berdasarkan Tabel 1, confusion matrix digunakan sebagai metode validasi data dari jumlah opini negatif dan positif yang tidak seimbang.Metode ini digunakan untuk mencari precision dan recall, terdapat istilah dari tabel confusion matrix diatas yaitu : [4]

1. TN yaitu True Negative, prediksi jumlah data negatif yang benar dari sistem klasifikasi multi-layer perceptron.

2. TP yaitu True Positif, prediksi jumlah data positif yang benar dari sistem klasifikasi multi-layer perceptron.

3. FP yaitu False Positive, prediksi jumlah data positif yang salah dari sistem klasifikasi multi-layer perceptron.

4. FN yaitu False Negative, prediksi jumlah data negatif yang salah dari sistem klasifikasi multi-layer perceptron.

a. Accuracy yaitu jumlah prediksi dataset yang benar dari tabel confusion matrix diatas.Sehingga ditentukan dari persamaan :

$$
\text { Accuracy }=\frac{T N+T P}{T N+T P+F P+F N}
$$

b. Precision, yaitu rasio dari jumlah positif yang benar dan jumlah positif yang salah.Sehingga ditentukan dari persamaan :

$$
\text { Precision }=\frac{T P}{T P+F P}
$$


c. Recall, yaitu rasio dari jumlah positif yang benar dengan jumlah positif yang benar ditambah dengan jumlah negatif yang salah.Sehingga ditentukan dari persamaan :

$$
\text { Recall }=\frac{T P}{T P+F N}
$$

d. F-measure atau bisa disebut dengan $f$-1 score adalah menyeimbangkan antar nilai precision dan recall.Sehingga ditentukan dari persamaan :

$$
F 1=\frac{2 \times(\text { precision } \times \text { recall })}{(\text { precision }+ \text { recall })}
$$

\section{HASIL DAN PEMBAHASAN}

Dalam penelitian ini pengujian model dilakukan dengan menggunakan final dataset dengan 3686 data yang didalamnya terdapat field text atau opini ditwitter, label biasanya berisi positif dengan nilai 1 dan negatif dengan nilai -1 , terkahir adalah user yang nantinya akan dihilangkan pada tahap pre-processing.Dan yang dibutuhkan hanya field text atau opini dan label.

\section{a. Hasil Pengujian}

Pengujian menggunakan tanpa model selection dan dengan model selection Monte Carlo Cross-validation dengan $n \_s p l i t$ berjumlah 10.Setiap $n \_s p l i t$ terdapat 10 skenario. Setiap skenario memiliki jumlah Learning Rate, Hidden Layer, Data Suffling dan alpha yang berbeda-beda. Tabel berikut sebagai hasil rata-rata dari seluruh $n \_s p l i t$ pada tiap-tiap model :

\begin{tabular}{|c|c|c|c|c|c|c|c|c|c|c|}
\hline \multirow[b]{2}{*}{ Model } & \multicolumn{4}{|c|}{ Skenario } & \multicolumn{6}{|c|}{ Hasil Rata-Rata } \\
\hline & $\begin{array}{l}\text { Hidden } \\
\text { Layers }\end{array}$ & $\begin{array}{c}\text { Learning } \\
\text { Rate }\end{array}$ & $\begin{array}{c}\text { Data } \\
\text { Suffling }\end{array}$ & $\begin{array}{c}\text { Dropout } \\
\text { (alpha) }\end{array}$ & $\begin{array}{l}\text { Train } \\
\text { Accur } \\
\text { acy }\end{array}$ & $\begin{array}{c}\text { Test } \\
\text { Accura } \\
\text { cy }\end{array}$ & $\begin{array}{c}\text { Precisi } \\
\text { on }\end{array}$ & Recall & F-1 & $\begin{array}{c}\text { Accura } \\
\text { cy }\end{array}$ \\
\hline MLP_01 & 32 & 0.001 & True & 0.0001 & 99.63 & 92.96 & 97.22 & 93.11 & 95.11 & 92.96 \\
\hline MLP_02 & 32 & 0.005 & True & 0.01 & 99.66 & 92.51 & 97.40 & 92.30 & 94.77 & 92.51 \\
\hline MLP_03 & 32 & 0.001 & False & 0.0001 & 99.64 & 92.88 & 97.22 & 93.00 & 95.05 & 92.88 \\
\hline MLP_04 & 64 & 0.001 & True & 0.001 & 99.64 & 93.03 & 97.13 & 93.30 & 95.17 & 93.03 \\
\hline MLP_05 & 64 & 0.001 & False & 0.0001 & 99.66 & 93.11 & 96.93 & 93.62 & 95.24 & 93.11 \\
\hline MLP_06 & 64 & 0.001 & True & 0.1 & 99.66 & 92.66 & 97.62 & 92.30 & 94.87 & 92.66 \\
\hline MLP_07 & 128 & 0.005 & False & 0.0001 & 99.66 & 93.26 & 96.54 & 94.21 & 95.36 & 93.26 \\
\hline MLP_08 & 128 & 0.1 & True & 0.0001 & 99.51 & 92.88 & 96.73 & 93.52 & 95.08 & 92.88 \\
\hline MLP_09 & 128 & 0.0005 & True & 0.0001 & 99.63 & 92.81 & 96.81 & 93.31 & 95.02 & 92.81 \\
\hline MLP_10 & 128 & 0.001 & True & 0.0001 & 99.66 & 93.11 & 96.93 & 93.61 & 95.23 & 93.11 \\
\hline
\end{tabular}

Tabel 2 Hasil Rata-Rata Pengujian 
Techno.COM, Vol. 19, No. 3, Agustus 2020: 237-244

Hasil Pengujian Monte Carlo Cross-Validation Pada Setiap Skenario

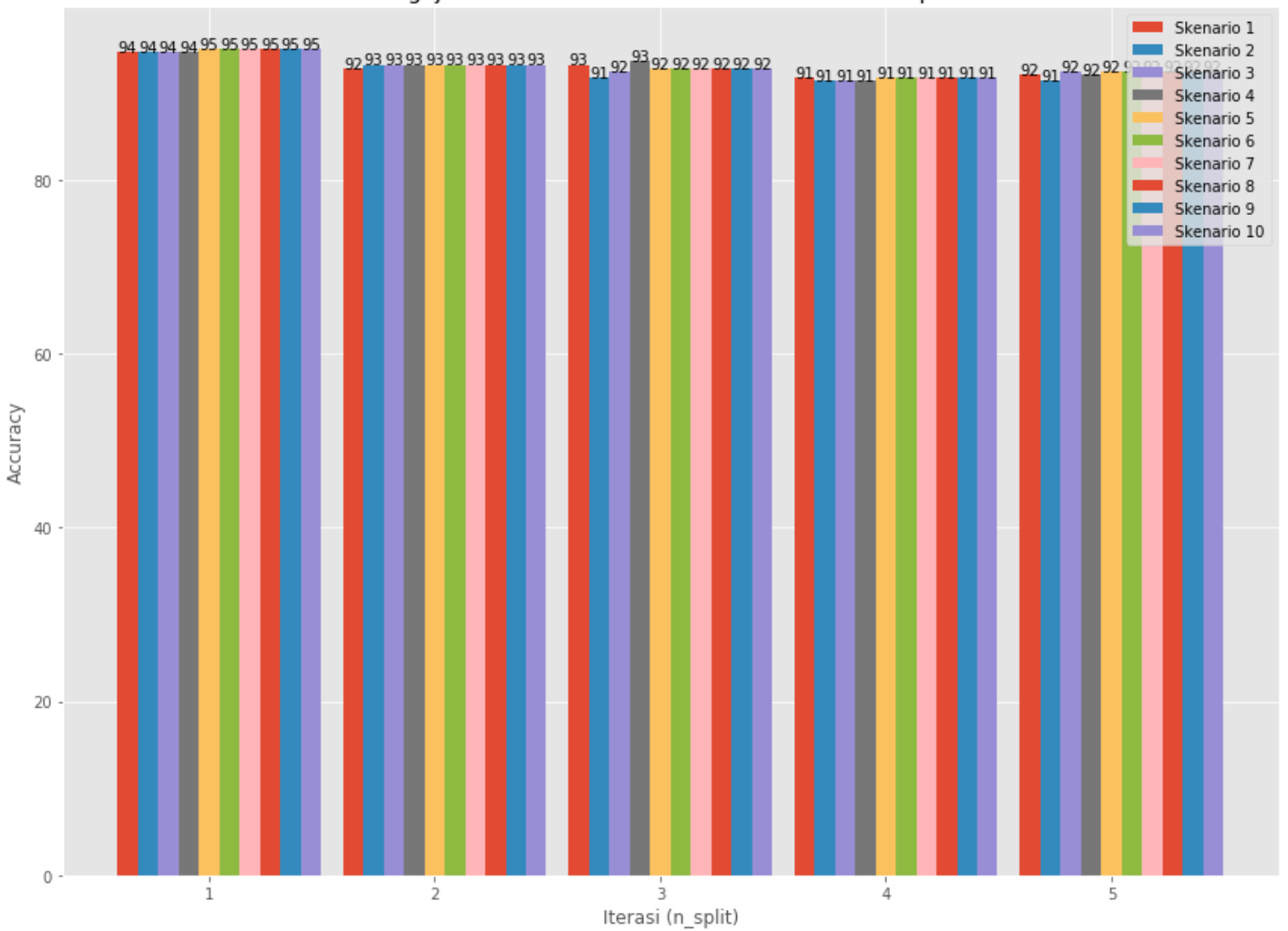

Gambar 1 Grafik Hasil Pengujian Monte Carlo Cross-Validation Pada Setiap Skenario

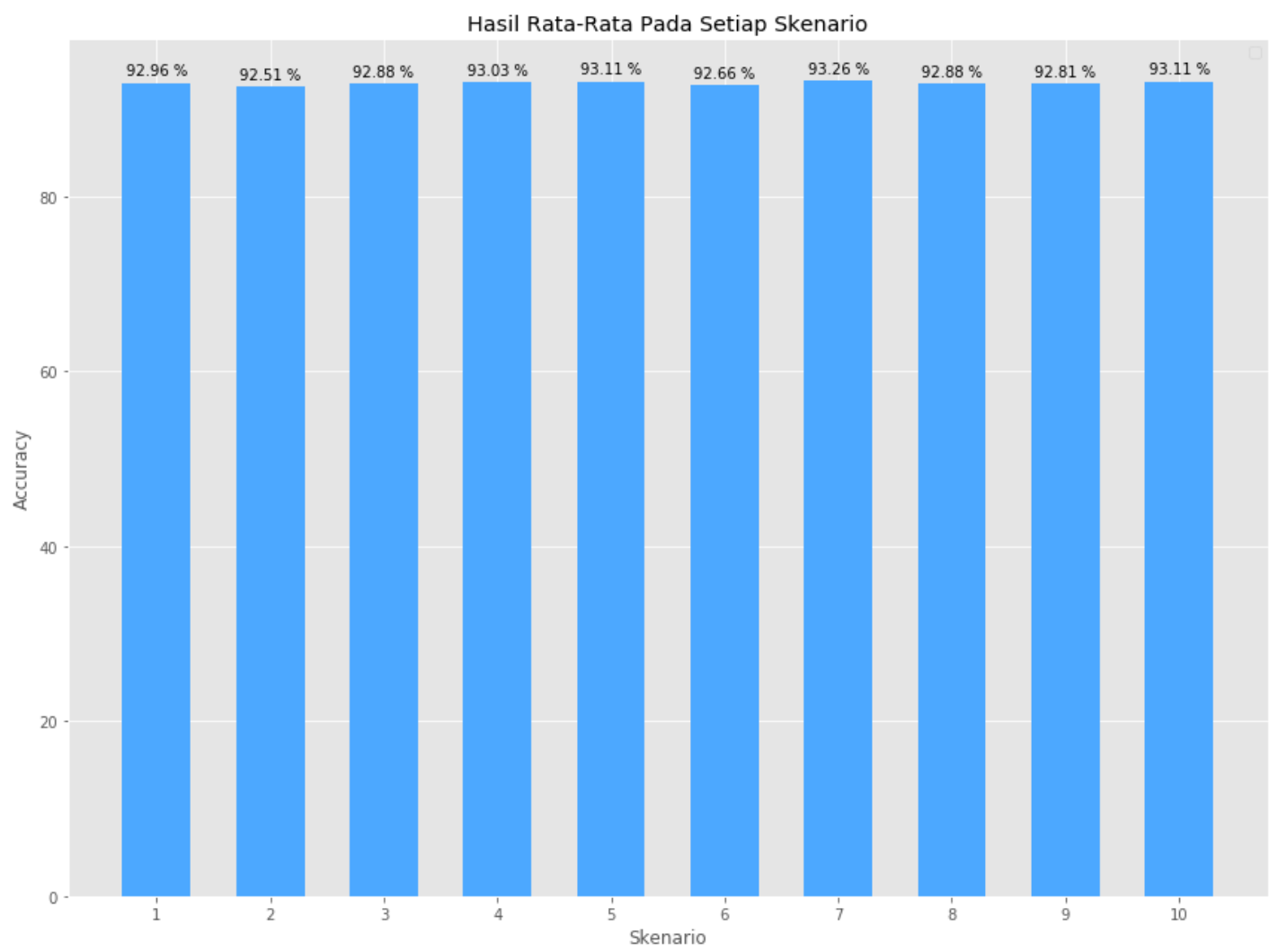

Gambar 2 Grafik Hasil Rata-Rata Pada Setiap Skenario 


\section{b. Analisis Hasil Pengujian}

Dari tabel 2 dapat disimpulkan bahwa skenario atau model ke 7 dengan Learning rate 0.005, menggunakan Hidden Layer sebanyak 64 Layer dan tidak menggunakan pengacakan data karena pengacakan data sudah dilakukan dengan model selection Monte carlo crossvalidation.Jika menggunakan pengacakan data lagi maka akan dilakukan dua kali sehingga dapat memperngaruhi hasil persentase akurasi, sehingga skenario ke tujuh mendapat hasil nilai akurasi terbaik pada perhitungan Accuracy 93,26\% dan nilai f1 atau F-measure dengan persentase 95,36 \% juga nilai Recall terbaik dengan persentase 94.21.

Pada skenario ke 2 (dua) atau model ke dua dengan Learning rate 0.005 , menggunakan Hidden Layer sebanyak 32 Layer dan menggunakan pengacakan data dari Monto carlo crossvalidation dan parameter model atau skenario ke 2.Sehingga skenario ke 2 (dua) mendapatkan hasil nilai Precision terbaik pada perhitungan precision $97.30 \%$.

Kemudian dari Gambar 1 dapat disimpulkan bahwa terjadinya perhitungan dari akurasi yang didapatkan oleh setiap skenario tiap-tiap $n \_s p l i t$. Setiap $n \_s p l i t$ memiliki Data Train dengan opini positif dan negative yang berbeda-beda dan kemudian dilakukan balancing data agar terhindar dari data yang tidak simbang atau overfitting data. Maka dari itu terjadi perhitungan terhadap akurasi. Sejak n_split pertama sampai dengan n_split terakhir, Skenario ke 7 (tujuh) mendapatkan hasil akurasi yang terbaik dari skenario yang lain.

Dapat diketahui dari hasil pengujian diatas bahwa jumlah Learning rate , Hidden layer, Drop out, dan pengacakan data akan berpengaruh terhadap nilai akurasi. Besarnya hidden layer tidak akan menjamin hasil akurasi menjadi lebih baik dengan Hidden layer yang lebih sedikit begitupun juga dengan Learning rate.Jumlah opini dari dataset yaitu positif dan negatif akan berpengaruh besar dalam menentukan akurasi dari model atau skenario.Jika data tidak seimbang maka harus diseimbangkan agar model atau skenario dapat dijalankan.

\section{KESIMPULAN}

1. Hasil Pengujian menunjukan bawha accuracy algoritma Multi-layer perceptron dengan jumlah Hidden layer, Learning Rate, Shuffling dan Drop Out berpengaruh dari nilai akurasi yang dihasilkan, Skenario 7 dengan menggunakan dataset presiden jokowi dan jumlah Hidden layer sebanyak 128 layer dan tidak menggunakan pengacakan data, sehingga mendapatkan perhitungan nilai akurasi terbaik pada Accuracu atau Test Accuracy dengan persentase 93,26\% dan nilai f1 atau F-measure dengan persentase 95,36 \% juga nilai Recall terbaik dengan persentase $94.21 \%$.

2. Jumlah pada Hidden Layer tidak akan menjamin membuat sebuah akurasi menjadi lebih baik karena terbukti dari skenario 9 dengan Hidden Layer berjumlah 128 mendapatkan persentase accuracy 92.81 .

3. Semakin tinggi nilai Learning rate maka akan mempengaruhi tingginya nilai akurasi pada tiaptiap skenario karena terbukti pada skenario tujuh didapatkan persentase nilai akurasi $93,26 \%$ dan skenario delapan dengan persentase nilai akurasi $92,88 \%$.

\section{SARAN}

Dalam penilitian ini dataset yang digunakan adalah dataset hasil crawling twitter dengan hashtag presiden jokowi dimana Dataset diperoleh Corpus sejumlah 42 dimana tiap-tiap corpus berisi 90-100 baris kalimat dengan 3 kolom yaitu label/sentiment, teks/tweet dan user.Kemudian semua corpus yang berjumlah 42 digabung menjadi final dataset dengan total 3686 baris dan 3 kolom.Maka selanjutnya akan dilakukan penelitian dengan jumlah dataset yang lebih besar,Kemudian karena penelitian ini menggunakan dataset berbahasa inggris dari crawling ditwitter maka selanjutnya dataset yang akan digunakan adalah menggunakan bahasa Indonesia. 


\section{DAFTAR PUSTAKA}

[1] I. F. Rozi et al., "Analisis Mengenai Calon Presiden Indonesia 2019 Di,” pp. 27-31, 2019.

[2] M. A. Assuja and S. Saniati, "Analisis Sentimen Tweet Menggunakan Backpropagation Neural Network," J. Teknoinfo, vol. 10, no. 2, p. 48, 2016, doi: 10.33365/jti.v10i2.20.

[3] R. Collobert, J. Weston, L. Bottou, M. Karlen, K. Kavukcuoglu, and P. Kuksa, "Natural language processing (almost) from scratch," J. Mach. Learn. Res., vol. 12, pp. 24932537, 2011.

[4] M. F. Muzakki, R. F. Umbara, F. Informatika, and U. Telkom, "Analisis Sentimen Mahasiswa Terhadap Fasilitas Universitas Telkom Menggunakan Metode Jaringan Saraf Tiruan Dan Tf-Idf," vol. 6, no. 2, pp. 8608-8616, 2019.

[5] G. A. Miller, R. Beckwith, C. Fellbaum, D. Gross, and K. J. Miller, "Introduction to wordnet: An on-line lexical database," Int. J. Lexicogr., vol. 3, no. 4, pp. 235-244, 1990, doi: 10.1093/ijl/3.4.235.

[6] S. Rosenthal, P. Nakov, A. Ritter, and V. Stoyanov, "SemEval-2014 Task 9: Sentiment Analysis in Twitter," 2019, [Online]. Available: http://arxiv.org/abs/1912.02990.

[7] S. Al-Azani and E. S. M. El-Alfy, "Using Word Embedding and Ensemble Learning for Highly Imbalanced Data Sentiment Analysis in Short Arabic Text," Procedia Comput. Sci., vol. 109, pp. 359-366, 2017, doi: 10.1016/j.procs.2017.05.365.

[8] C.-F. Tsai, "Bag-of-Words Representation in Image Annotation: A Review," ISRN Artif. Intell., vol. 2012, pp. 1-19, 2012, doi: 10.5402/2012/376804.

[9] K. R. SPORNE, "the Phylogenetic Classification of the Angiosperms," Biol. Rev., vol. 31, no. 1, pp. 1-29, 1956, doi: 10.1111/j.1469-185X.1956.tb01550.x.

[10] A. Elmessiry, W. O. Cooper, T. F. Catron, J. Karrass, Z. Zhang, and M. P. Singh, "Triaging Patient Complaints: Monte Carlo Cross-Validation of Six Machine Learning Classifiers," JMIR Med. Informatics, vol. 5, no. 3, p. e19, 2017, doi: 10.2196/medinform.7140.

[11] V. Singh and B. Saini, "An Effective Tokenization Algorithm for Information Retrieval Systems,” pp. 109-119, 2014, doi: 10.5121/csit.2014.4910.

[12] A. I. Kadhim, Y. N. Cheah, and N. H. Ahamed, "Text Document Preprocessing and Dimension Reduction Techniques for Text Document Clustering," Proc. - 2014 4th Int. Conf. Artif. Intell. with Appl. Eng. Technol. ICAIET 2014, pp. 69-73, 2015, doi: 10.1109/ICAIET.2014.21.

[13] S. Chithore, "International Journal of Advance Engineering and Research Sentiment Analysis with Multilayer Perceptron using Emoticon Space Model," pp. 410-419, 2017.

[14] M. S. Akhtar, A. Kumar, D. Ghosal, A. Ekbal, and P. Bhattacharyya, "A Multilayer perceptron based ensemble technique for fine-grained financial sentiment analysis," EMNLP 2017 - Conf. Empir. Methods Nat. Lang. Process. Proc., pp. 540-546, 2017, doi: $10.18653 / \mathrm{v} 1 / \mathrm{d} 17-1057$.

[15] S. Budi, "Text Mining Untuk Analisis Sentimen Review Film Menggunakan Algoritma K-Means," Techno.Com, vol. 16, no. 1, pp. 1-8, 2017, doi: 10.33633/tc.v16i1.1263. 